\title{
Control design of fin roll stabilization in beam seas based on Lyapunov's direct method
}

\author{
Safak C. Karakas, M. Sc. \\ Erdem Ucer, Ph. D. \\ Istanbul Technical University \\ Emre Pesman, Ph. D. \\ Karadeniz Technical University
}

\begin{abstract}
The aim of this study is to design a controller based on Lyapunov's direct method for fin roll stabilization systems for ships in beam seas. A third order mathematical model consisting of uncoupled roll motion of a ship and fin hydraulic system dynamics is considered. In the model, random wind force is defined by Gaussian white noise. Both controlled and uncontrolled roll motions are presented considering stall effect by roll-time history and safe basin graphics. It is observed from the results that fin control system is successful to reduce erosion percentages of safe basins and roll amplitudes.
\end{abstract}

Keywords: fin stabilizers; Lyapunov function; roll motion; white noise

\section{INTRODUCTION}

Large amplitude rolling motion is one of the dangerous phenomenon leading to capsizing of a ship in moderate and rough beam seas so it should be reduced by passive controllers such as bilge keels and active controllers such as fins, anti roll tanks, etc. The effectiveness of bilge keels is limited [1] so active fins are used when a more effective control action is needed to reduce rolling motion. Numerous studies on ship stabilization by using fin controllers are available since 1940s. The required moment to hold a ship against the upsetting moment of regular sea was investigated with model fin tests by Allan [2]. The performance of active stabilizers in the two trial ship was represented theoretically with reasonable accuracy by Conolly [3]. In 1993, a free running ship model equipped with active fin stabilizers was used to explore the nature of roll stabilizing problem and from the results of this experiment important hull-fin and fin-hull interferences were identified by Dallinga [4]. Ship stabilizing fin controller based on the internal model control (IMC) method was described by Tzeng and $\mathrm{Wu}$ [5]. In the study of Yang et al. [6], a robust adaptive fuzzy controller was constructed, a stability theorem for the proposed robust adaptive fuzzy scheme was proved and it was demonstrated how the robust adaptive fuzzy control scheme could be applied to the controller design for ship roll stabilization. The choice of controller for a fin-stabilization system on the effect of operational performance of the ship was presented by Crossland [7]. The design and implementation of a robust $\mathrm{H}-\infty$ controller designed to stabilize the roll motion of a ship was presented by Hickey et al. [8]. The ship roll stabilization by fin control system with actuator was considered by Yang and Jiang [9] and it was shown that the designed system guaranteed the performance of robustness with respect to the perturbations and uncertainties. Nonlinear roll motion of a frigate ship using a pair of fins activated by a PID control system was presented by Surendran et al. [10]. Constrained predictive control of ship fin stabilizers to prevent dynamic stall was presented by Perez and Goodwin [11]. Robust control of ship fin stabilizers subject to disturbances and constraints was presented by Ghaemi et al. [12]. The simulation results of that study show that the proposed robust control method reduces the ship roll motion while satisfying the input and dynamic stall constraints. Stabilization of parametric roll resonance in moderate head and following seas by combined speed and fin stabilizer control based on Lyapunov's direct method is presented by Galezzi et al. [13]. A combined neural network and PID for roll control of ship with small draught considering hydraulic machinery constraints is presented by Ghassemi et al. [14].

In this study, a fin controller based on Lyapunov's direct method is designed in order to reduce severe rolling motion of ship in steady beam seas under the influence of random wind force. The effectiveness of the controller is tested by comparing controlled and uncontrolled roll angle simulations for different initial conditions considering stall effect. In order to succeed this type of comparison, safe basin concept [15] is used. In that method, the safe and capsizing initial conditions are represented by white and black points respectively and the effects of different initial conditions on the stability of the dynamic system (ship) can be shown by using just one graphic. From the comparisons of safe basins plots of controlled and uncontrolled roll motion, it is seen that the controller is successful. 


\section{SHIP MODELING FOR FIN STABILIZER CONTROL SYSTEM DESIGN}

\section{Equations of ship motion}

In beam seas, roll motion has a greater influence on ship stability rather than the other modes of ship motion. Due to the difficulty of accurately determining the complete hydrodynamic forces, a rolling model which decouples the six degrees of freedom is generally assumed. In most of the studies, coupling of roll and sway motions are considered for the purpose of ship stability analysis [16]. The two degree of freedom roll and sway model is reduced to a 1-DOF rolling model by introducing a virtual roll centre $[16,17,18]$. Assuming the ship has a rigid body and seawater is ideal and incompressible, the uncoupled roll model is defined by Eq. 1 .

$$
\mathrm{I} \ddot{\phi}+\mathrm{B}_{\mathrm{E}} \dot{\phi}+\Delta \mathrm{GZ}(\phi)=\mathrm{E}_{0} \cos (\omega \mathrm{t})+\mathrm{Z} \xi(\mathrm{t})+\mathrm{C}
$$

where

$\phi \quad$ - rolling angle with respect to calm sea surface (rad),

$\dot{\phi}-$ roll angular velocity $(\mathrm{rad} / \mathrm{s})$,

I - virtual moment of inertia corresponds to a virtual (physical) axis of rotation, located at the virtual ship mass center (the mass center of the ship),

$\Delta$ - the buoyancy force,

$\omega-$ the wave circular frequency.

$\mathrm{GZ}$ - the righting arm as a function of the roll angle and defined by as follows:

$$
\mathrm{GZ}(\phi)=\mathrm{GM} \phi+\mathrm{c}_{3} \phi^{3}+\mathrm{c}_{5} \phi^{5}+\mathrm{c}_{7} \phi^{7}
$$

where:

$\phi \quad$ - the angle of heel,

GM - the initial metacentric height.

$\mathrm{E}_{\mathrm{o}}$ - the amplitude of wave excitation and defined by as follows:

$$
\mathrm{E}_{0}=\kappa \frac{\pi \mathrm{h}_{\mathrm{w}}}{\lambda_{\mathrm{w}}} \Delta \mathrm{GM}
$$

where:

$\kappa-$ the reduction coefficient for the effective wave slope, $\mathrm{h}_{\mathrm{w}}$ is the wave amplitude,

$\lambda_{\mathrm{w}}-$ the wave length, the wave slope $\left(\pi \mathrm{h}_{\mathrm{w}} / \lambda_{\mathrm{w}}\right)$ is taken smaller than $11^{\circ}$.

$\mathrm{B}_{\mathrm{E}}$ - equivalent linear damping coefficient and defined as follows:

$$
\mathrm{B}_{\mathrm{E}}=\mathrm{B}_{\mathrm{w}}+\mathrm{B}_{\mathrm{F}}+\mathrm{B}_{\mathrm{e}}+\mathrm{B}_{\mathrm{L}}+\mathrm{B}_{\mathrm{BK}}
$$

where:

$\mathrm{B}_{\mathrm{F}}-$ friction damping,

$\mathrm{B}_{\mathrm{e}}$ - eddy damping,

$\mathrm{B}_{\mathrm{L}}$ - lift damping

$\mathrm{B}_{\mathrm{BK}}-$ bilge keel damping coefficient. These coefficients are determined by semi-empirical formulas given by Himeno [19].

$\mathrm{B}_{\mathrm{w}}$ - wave damping coefficient and can be determined by SHIPMO program [20]. Although these coefficients are seemingly linear, their values may vary with the roll amplitude and the wave frequency [19] and also the interactions among these damping components are ignored.

$\xi(\mathrm{t})$ - random wind force defined by Gaussian white noise.

$\mathrm{Z}$ - diffusion constant.

$\mathrm{C}-$ the control moment produced by the fins.

Eq. 5 is obtained by dividing the both sides of Eq. 1 by the virtual moment of inertia (I).

$$
\begin{gathered}
\ddot{\phi}+b_{\mathrm{E}} \dot{\phi}+\omega_{0}^{2} \phi+\mathrm{c}_{3}^{*} \phi^{3}+\mathrm{c}_{5}^{*} \phi^{5}+\mathrm{c}_{7}^{*} \phi^{7}= \\
=\mathrm{e}_{0} \cos (\omega \mathrm{t})+\sigma \xi(\mathrm{t})+\tau_{\mathrm{c}}
\end{gathered}
$$

where:

$$
\begin{aligned}
\omega_{\mathrm{o}} & =\sqrt{\frac{\Delta \mathrm{GM}}{\mathrm{I}}}, \\
\mathrm{b}_{\mathrm{E}} & =\mathrm{B}_{\mathrm{E}} / \mathrm{I}, \\
\mathrm{c}^{*}{ }_{3} & =\mathrm{c}_{3} / \mathrm{I}, \\
\mathrm{c}^{*}{ }_{5} & =\mathrm{c}_{5} / \mathrm{I}, \\
\mathrm{c}^{*}{ }_{7} & =\mathrm{c}_{7} / \mathrm{I}, \\
\mathrm{e}_{\mathrm{o}} & =\mathrm{E}_{\mathrm{o}} / \mathrm{I}, \\
\sigma & =\mathrm{Z} / \mathrm{I} \\
\tau_{\mathrm{c}} & =\mathrm{C} / \mathrm{I} .
\end{aligned}
$$

\section{Control force}

The roll moment generated by fins is expressed as follows [11]:

$$
\tau_{\mathrm{c}}=\frac{\rho \mathrm{r}_{\mathrm{f}} \mathrm{V}_{\mathrm{fl}}^{2} A_{\mathrm{f}} \mathrm{C}_{\mathrm{L}}\left(\alpha_{\mathrm{e}}\right)}{\mathrm{I}}
$$

where:

$\rho-$ the water density,

$\mathrm{r}_{\mathrm{f}}$ - the fin moment arm,

$\mathrm{V}_{\mathrm{fl}}$ - the relative speed between the fins and the flow (which for control design can be approximated by the forward speed of the vessel $U$ (i.e., $V_{\mathrm{fl}} \approx \mathrm{U}$ ),

$A_{f}$ - the area of the fin,

$\mathrm{C}_{\mathrm{L}}-$ the lift coefficient,

$\alpha_{e}-$ the effective angle of attack between the fin and the fluid velocity [11].

The increment of lift coefficient $\mathrm{C}_{\mathrm{L}}$ due to angle of attack is approximately linear to the particular angle called stall angle as defined in Eq. 7 [11].

$$
\mathrm{C}_{\mathrm{L}}\left(\alpha_{\mathrm{e}}\right) \approx \overline{\mathrm{C}}_{\mathrm{L}} \alpha_{\mathrm{e}} \text {, with }\left.\overline{\mathrm{C}}_{\mathrm{L}} \triangleq \frac{\partial \mathrm{C}_{\mathrm{L}}}{\partial \alpha_{\mathrm{e}}}\right|_{\alpha_{\mathrm{e}}=0}
$$

Exceeding stall angle causes decrement of the lift and causes the controller not working properly.

The effective angle of attack is defined as follows:

where:

$$
\alpha_{\mathrm{e}}=-\alpha_{\mathrm{pu}}-\alpha_{\mathrm{m}}
$$

$\alpha_{\mathrm{m}}$ - the mechanical angle of the fins (control command),

$\alpha_{\mathrm{pu}}-$ the flow angle induced by the combination of forward speed and roll rate [11] and defined as follows:

$$
\alpha_{\mathrm{pu}}=\arctan \left(\frac{\mathrm{r}_{\mathrm{f}} \dot{\phi}}{\mathrm{U}}\right) \approx \frac{\mathrm{r}_{\mathrm{f}}}{\mathrm{U}} \dot{\phi}
$$

The total roll moment induced by the fins can then be approximated by

where:

$$
\tau_{\mathrm{c}}=\mathrm{K}_{\alpha}\left(\frac{\mathrm{r}_{\mathrm{f}}}{\mathrm{U}} \dot{\phi}-\alpha_{\mathrm{m}}\right)
$$

$\mathrm{K}_{\alpha}=\rho \mathrm{r}_{\mathrm{f}} \mathrm{V}_{\mathrm{fl}}^{2} \mathrm{~A}_{\mathrm{f}} \overline{\mathrm{C}}_{\mathrm{L}} / 1$

\section{CONTROL SYSTEM DESIGN}

The uncoupled roll motion Eq. 5 is defined by the equation system as follows:

$$
\begin{gathered}
\mathrm{F}_{1}=\mathrm{x}_{2} \\
\mathrm{~F}_{2}=-\left(\mathrm{b}_{\mathrm{e}}+\mathrm{K}_{\alpha} \frac{\mathrm{r}_{\mathrm{f}}}{\mathrm{U}}\right) \mathrm{x}_{2}-\left(\omega_{0}^{2} \phi+\mathrm{c}_{3}^{*} \phi^{3}+\mathrm{c}_{5}^{*} \phi^{5}+\mathrm{c}_{7}^{*} \phi^{7}\right)+ \\
+\mathrm{e}_{0} \cos (\omega \mathrm{t})-\mathrm{K}_{\alpha} \alpha_{\mathrm{m}}
\end{gathered}
$$

by considering the states as $\mathrm{x}_{1}=\phi$ and $\mathrm{x}_{2}=\dot{\phi}$. 


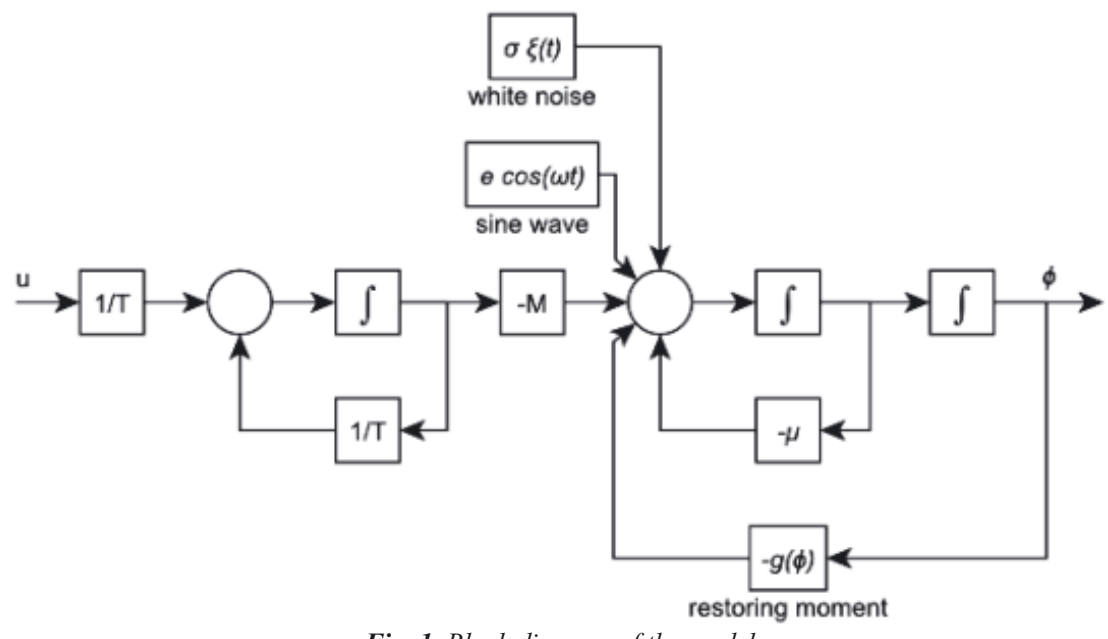

Fig. 1. Block diagram of the model

The Lyapunov function candidate of the system is as follows:

$$
\mathrm{V}=\frac{\mathrm{x}^{2}}{2}+\left(\omega_{0}^{2} \frac{\mathrm{x}_{1}^{2}}{2}+\mathrm{c}_{3}^{*} \frac{\mathrm{x}_{1}^{4}}{4}+\mathrm{c}_{5}^{*} \frac{\mathrm{x}_{1}^{6}}{6}+\mathrm{c}_{7}^{*} \frac{\mathrm{x}_{1}^{8}}{8}\right)
$$

When the Lyapunov function is substituted in the differential generator of the stochastic process [21], the following relation is obtained.

$$
\begin{gathered}
\mathrm{LV}=\left(\alpha^{2} \mathrm{x}_{1}^{2}+\mathrm{e}_{0} \cos (\omega \mathrm{t})\right) \mathrm{x}_{2}< \\
<\mathrm{K}_{\alpha} \alpha_{\mathrm{m}} \mathrm{x}_{2}+\left(\mathrm{b}_{\mathrm{e}}+\frac{\mathrm{r}_{\mathrm{f}}}{\mathrm{U}}\right) \mathrm{x}_{2}^{2}
\end{gathered}
$$

When the equality $\mathrm{LV}<0$ is verified, the ship is stable and the required mechanical angle of the fins $\left(\alpha_{\mathrm{m}}\right)$ is determined as follows:

$$
\alpha_{\mathrm{m}}=\frac{1}{\mathrm{f}_{1}}\left(\sigma^{2} \mathrm{x}_{1}^{2}+\mathrm{e}_{0} \cos (\omega \mathrm{t})\right)
$$

By means of a electrohydraulic system, two fins are driven and create an additional righting moment. The actuator can approximately be described by a $1^{\text {st }}$ order equation as follows:

$$
\dot{\mathrm{x}}_{3}=-\frac{1}{\mathrm{~T}} \mathrm{x}_{3}+\frac{1}{\mathrm{~T}} \mathrm{u}
$$

where:

$\mathrm{x}_{3}-$ a state of the system and considered as $\mathrm{X}_{3}=\alpha_{\mathrm{m}}$,

$\mathrm{u}$ - the control input defined as the voltage input to the electro-valve of the hydraulic system [22].

The order fin angle due to time is obtained by substituting the required mechanical angle of fins into the Eq. 15 .

The block diagram of the whole model is seen in Fig. 1.

\section{NUMERICAL SIMULATIONS}

In the numerical simulations, a BSRA trawler [23] is used as a sample ship. Geometric particulars of the BSRA trawler are seen in Tab. 1.

Tab. 1. Geometric particulars of the BSRA trawler

\begin{tabular}{|c|c|}
\hline $\mathrm{L}_{\mathrm{BP}}(\mathrm{m})$ & 48.085 \\
\hline Beam $(\mathrm{m})$ & 8.289 \\
\hline Draught $(\mathrm{m})$ & 3.734 \\
\hline $\mathrm{L}_{\mathrm{WL}} / \mathrm{B}$ & 5.80 \\
\hline $\mathrm{B} / \mathrm{d}$ & 2.22 \\
\hline $\mathrm{D}(\mathrm{Ton})$ & 847 \\
\hline $\mathrm{C}_{\mathrm{B}}$ & 0.564 \\
\hline $\mathrm{C}_{\mathrm{WL}}$ & 0.775 \\
\hline $\mathrm{C}_{\mathrm{p}}$ & 0.627 \\
\hline
\end{tabular}

Comparisons of roll, roll angular velocity and mechanical angle of fins time histories of controlled and uncontrolled roll motion are shown in Fig. 2 when excitation amplitude is 0.06 , $\mathrm{K}_{\alpha}$ is 0.05 for $\phi_{\mathrm{o}}=0 \mathrm{rad}$ and $\dot{\phi}_{\mathrm{o}}=0.4 \mathrm{rad} / \mathrm{s}$. In the figure, black lines represent uncontrolled case whereas bold black lines represent controlled states. The controller is able to stabilize the system as seen in the figure.

Safe basin concept [15] is used to present the efficiency of controller. In the safe basin concept, the safe and capsizing initial conditions are represented by white and black areas respectively. The bounded area of initial conditions is expressed as follows:

$$
\left(\mathrm{x}_{1}, \mathrm{x}_{2}\right):-1.25 \leq \mathrm{x}_{1} \leq 1.25,-1.0 \leq \mathrm{x}_{2} \leq 1.0
$$

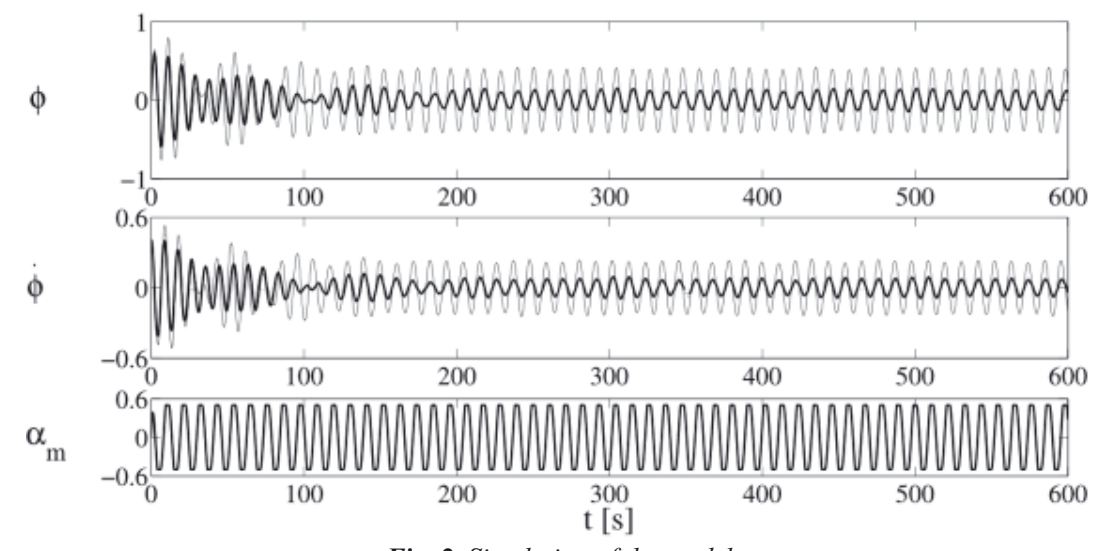

Fig. 2. Simulation of the model 
where $\mathrm{x}_{1}$ is in radians and $\mathrm{x}_{2}$ is in $\mathrm{rad} / \mathrm{s}$. The bounded area is divided into $126 \times 101$ points and the lattice points are taken as the initial values for the solutions of Eq. 11. For each initial condition, a simulation of 1500 seconds is run.

In Figs 3 and 4, safe basins of controlled and uncontrolled roll motion of the BSRA trawler are presented for varying ship velocities $(\mathrm{U})$ and wave excitation amplitudes $\left(\mathrm{e}_{\mathrm{o}}\right)$ respectively

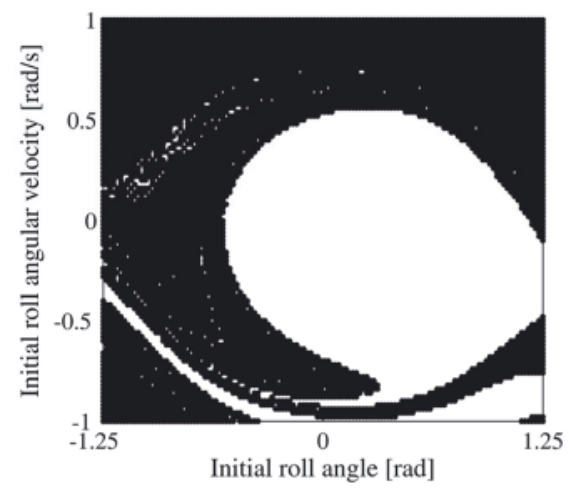

a) $\mathrm{U}=12 \mathrm{knots}$ - Uncontrolled

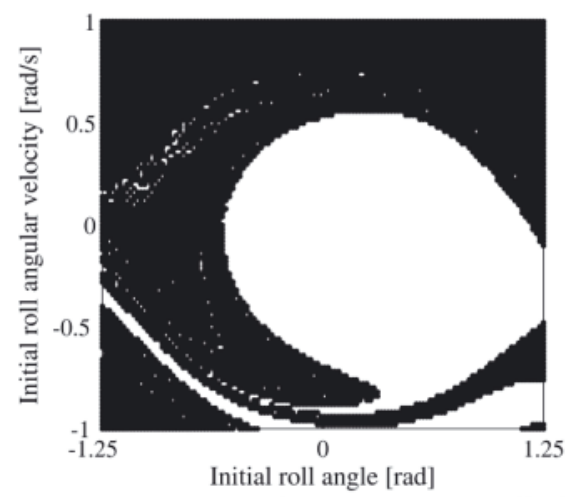

c) $\mathrm{U}=13$ knots - Uncontrolled

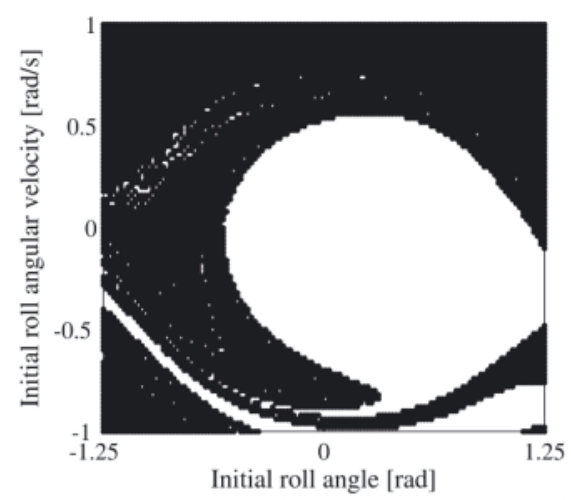

e) $\mathrm{U}=14$ knots - Uncontrolled

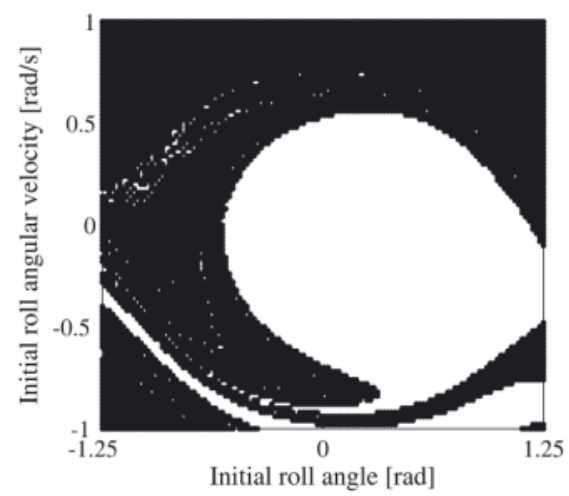

g) $\mathrm{U}=15$ knots - Uncontrolled when $\mathrm{K}_{\alpha}$ is 0.05 . For various ship velocities, the safe basin area of the controlled cases are larger than uncontrolled ones. By increasing the wave excitation amplitude, the safe region of uncontrolled roll motion (white area in the figures) decreases dramatically. By the help of the controller, safe basin enlarges. Therefore, Lyapunov designed controller is successful to reduce severe roll motion.

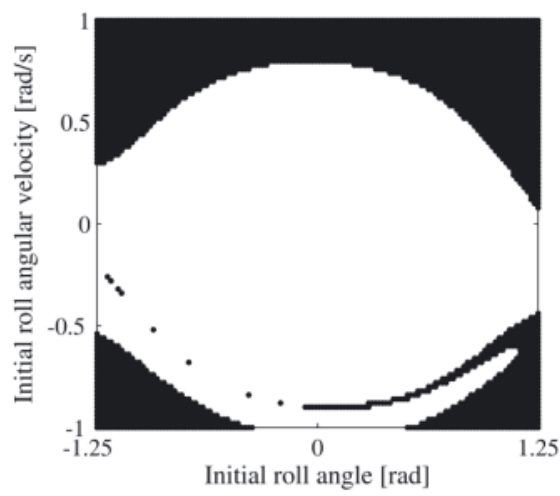

b) $\mathrm{U}=12$ knots - Controlled

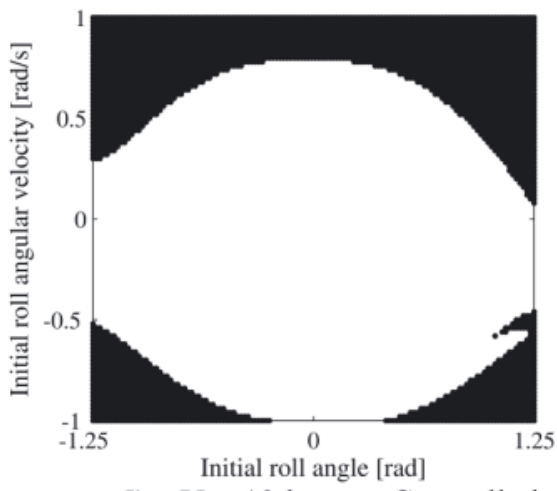

d) $\mathrm{U}=13 \mathrm{knots}$ - Controlled

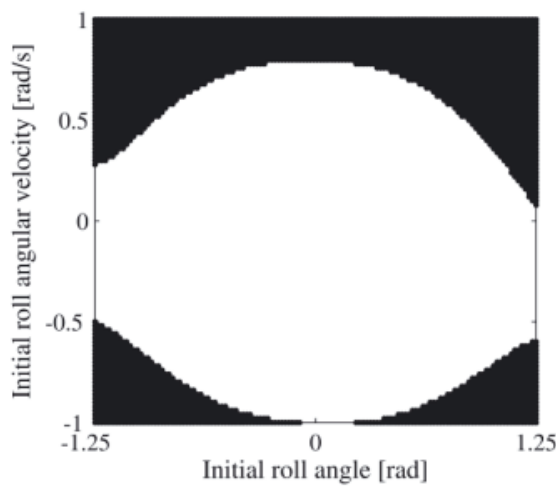

f) $\mathrm{U}=14$ knots - Controlled

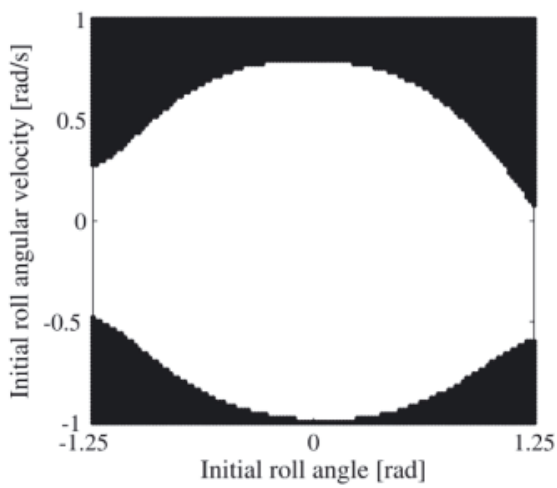

h) $\mathrm{U}=15$ knots - Controlled

Fig. 3. Safe Basins of Controlled and Uncontrolled Cases due to Ship Velocity 


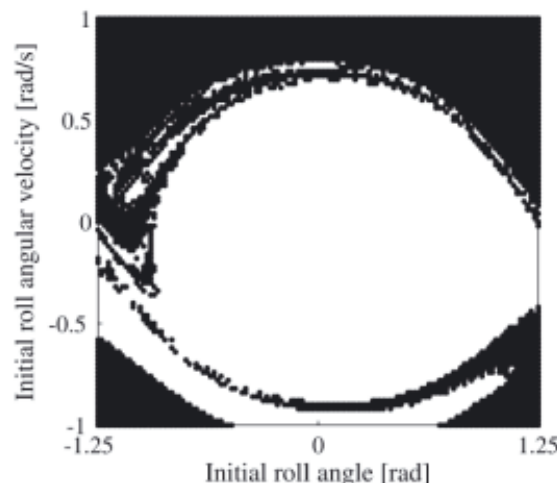

a) $\mathrm{e}_{\mathrm{o}}=0.04$ - Uncontrolled

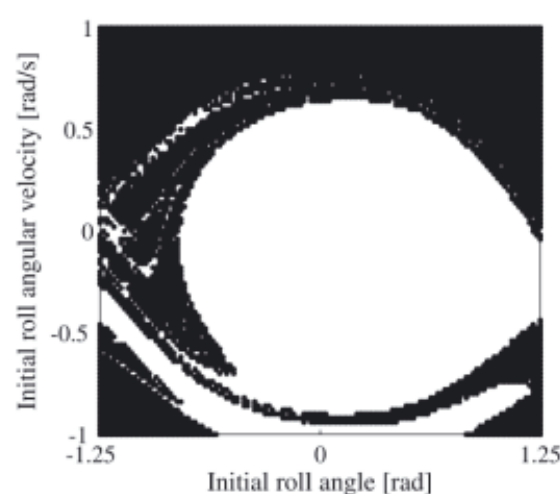

c) $\mathrm{e}_{\mathrm{o}}=0.05$ - Uncontrolled

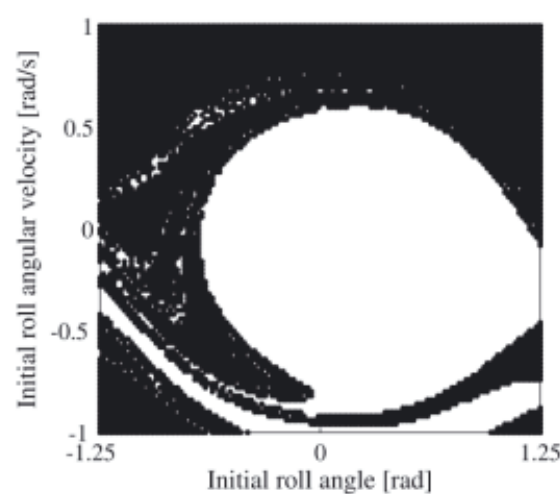

e) $\mathrm{e}_{\mathrm{o}}=0.06$ - Uncontrolled

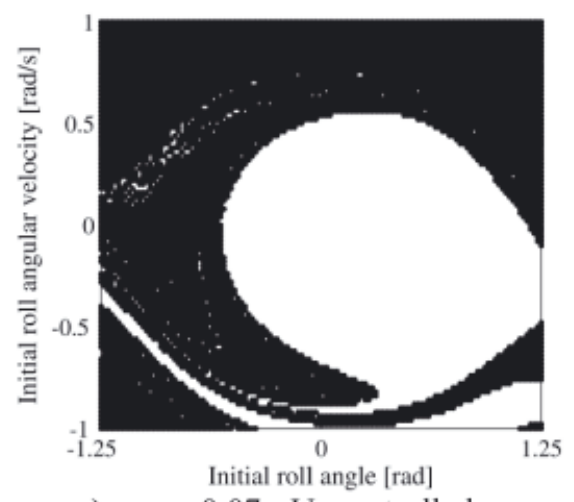

g) $\mathrm{e}_{\mathrm{o}}=0.07$ - Uncontrolled

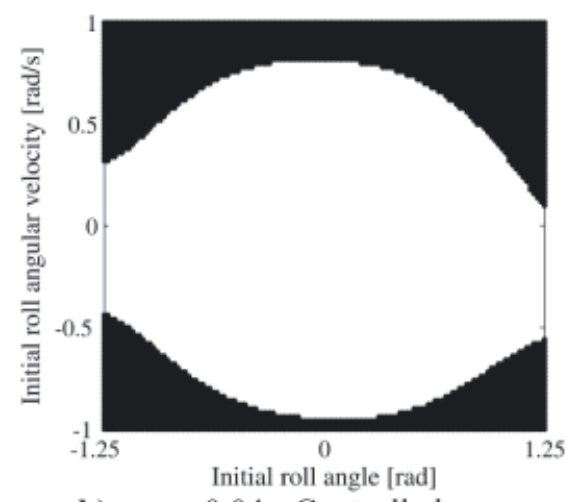

b) $\mathrm{e}_{\mathrm{o}}=0.04$ - Controlled

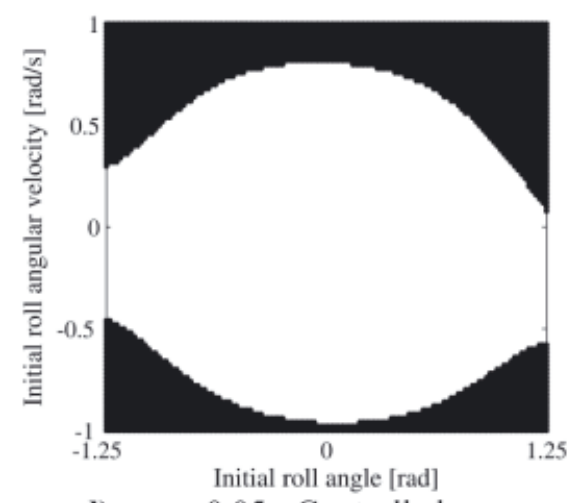

d) $\mathrm{e}_{\mathrm{o}}=0.05$ - Controlled

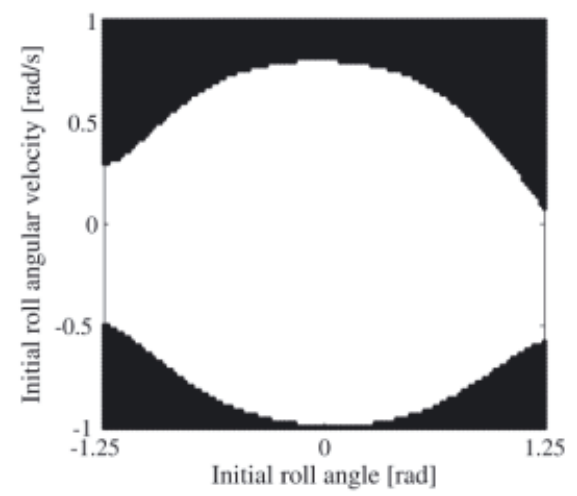

f) $\mathrm{e}_{\mathrm{o}}=0.06$ - Controlled

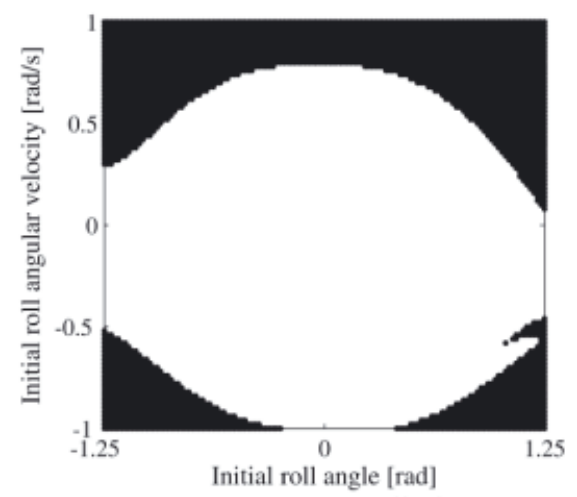

h) $\mathrm{e}_{\mathrm{o}}=0.07$ - Controlled

Fig. 4. Safe Basins of Controlled and Uncontrolled Cases due to Wave Excitation Amplitude

\section{CONCLUSION}

A controller based on Lyapunov's direct method is designed to reduce roll amplitudes and erosion of safe basins of ships in beam seas. Stability status of the sample ship in different initial conditions is presented by safe basin plots. Performance of fin control system is tested with respect to ship speed and wave amplitude. It is observed from the results that fin control system is successful to reduce erosion percentages of safe basins and roll amplitudes. However, even if the controller is used, roll amplitudes exceed a certain value for low ship speeds. Therefore, anti-roll tanks or gyroscopes which are independent from ship speed have to be used. Briefly, it is concluded that fin control system based on Lyapunov's direct method works 
properly and possibility of capsizing at speeds nearby service speed is significantly reduced by fin control system. For further studies, random wave force should be considered and also rolling in following seas can be examined.

\section{REFERENCES}

1. Ashraf A. Zaher, Nonlinear control of systems with multiple equilibria and unknown sinusoidal disturbance, Communications in Nonlinear Science and Numerical Simulation, vol.12, pages 1518-1533, 2007

2. J. F. Allan, Stabilisation of ships by activated fins, Transactions of the Royal Institution of Naval Architects RINA, vol.87, pages 123-159, 1945

3. J. E. Conolly, Rolling and its stabilization by active fins, Transactions of the Royal Institution of Naval Architects RINA, vol.111, pages 21-48, 1968

4. R. P. Dallinga, Hydromechanic aspects of the design of fin stabilisers, The Royal Institution of Naval Architects International Conference on Ship Motions \& Manoeuvrability, no.5, London, U.K., 1993

5. Ching-Yaw Tzeng and Chung-Yi Wu, On the design and analysis of ship stabilizing fin controller, Journal of Marine Science and Technology, vol.8, no.2, pages 117-124, 2000

6. Yansheng Yang, Changjiu Zhou and Xinle Jia, Robust adaptive fuzzy control and its application to ship roll stabilization, Information Sciences, vol.142, pages 177-194, 2002

7. P. Crossland, The effect of roll-stabilisation controllers on warship operational performance, Control Engineering Practice, vol.11, pages 423-431, 2003

8. N.A. Hickey, M.J. Grimble, M.A. Johnson, M.R. Katebi, and R. Melville, Robust Fin Roll Stabilisation of Surface Ships, Proceedings of the 36th Conference on Decision \& Control, pages 4225-4230, San Diego, Califomia USA, 1997, December

9. Yansheng Yang and Bo Jiang, Variable Structure Robust Fin Control for Ship Roll Stabilization with Actuator System, Proceeding of the 2004 American Control Conference, pages 5212-5217, Boston, Massachusetts, 2004, June 30 - July 2

10.S. Surendran, S.K. Leeb and S.Y. Kimb, Studies on an algorithm to control the roll motion using active fins, Ocean Engineering, vol.34, pages 542-551, 2007

11. Tristan Perez and Graham C. Goodwin, Constrained predictive control of ship fin stabilizers to prevent dynamic stall, Control Engineering Practice, vol.16, pages 482-494, 2008

12.Reza Ghaemi, Jing Sun and Ilya V. Kolmanovsky, Robust Control of Ship Fin Stabilizers Subject to Disturbances and Constraints, 2009 American Control Conference, Hyatt Regency Riverfront, St. Louis, MO, USA, 2009, June 10-12
13. Roberto Galeazzi, Christian Holden, Mogens Blanke and Thor I. Fossen, Stabilisation of Parametric Roll Resonance by Combined Speed and Fin Stabiliser Control, Proceedings of the European Control Conference, Budapest, Hungary, 2009, August 23-26

14.Hassan Ghassemi, Fatemeh Hoseini Dadmarzi, Parviz Ghadimi and Babak Ommani, Neural network-PID controller for roll fin stabilizer, Polish Maritime Research, vol.65, no.2, pages 23-28, 2010

15.J.M.T. Thompson, Loss of engineering integrity due to the erosion of absolute and transient basin boundaries, Proceedings of IUTAM Symposium on the Dynamics of Marine Vehicles and Structures in Waves, pages 313-320, 1989

16.C. Jiang, Highly nonlinear rolling motion leading to capsize, University of Michigan, Ann Arbor, 1995

17.B.L. Hutchison, The transverse plane motions of ships, SNAME Marine Technology, vol.28, no.2, pages 55-72, 1991

18.L. Balcer, Location of ship rolling axis, Polish Maritime Research, vol.11, no.1, pages 3-7, 2004

19.Y. Himeno, Prediction of ship roll damping-state of the art, UMICH, no.239, Ann Arbor, 1981

20.R.F. Beck and A.W. Troesch, Students documentation and users manual for the computer program SHIPMO.BM., Department of Naval Architecture and Marine Engineering, University of Michigan, Ann Arbor, 1990

21.H.J. Kushner, Stochastic stability and control, Academic Press, NewYork, 1967

22.Khac Duc Do and Jie Pan, Nonlinear robust fin roll stabilization of surface ships using neural networks, Proceedings of the 40th IEEE Conference on Desicion and Control, pages 2726-2731, Orlando, Florida USA, 2001

23.Pattullo, R.N.M. and G.R. Thomson, The BSRA Trawler Series, Part 1, Trans RINA, vol.107, no., pages 216-236, 1965

\section{CONTACT WITH THE AUTHORS}

Safak C. Karakas, M. Sc. Erdem Ucer, Ph. D.

Faculty of Naval Architecture and Ocean Engineering Istanbul Technical University e-mail: karakass@itu.edu.tr

Emre Pesman, Ph. D.

Surmene Faculty of Marine Science Karadeniz Technical University 